\title{
Miss, what's my name? New teacher identity as a question of reciprocal ontological security
}

\section{The new teacher in context}

Teachers are probably universally regarded as central to most formal systems of education. Less universal, however, is agreement on their role. The more extreme technocrats, for example, argue that developments in information technology and their social impact may render the role of the teacher in human form superfluous and/or even anachronistic. That there are situations outside education systems, and inside them, where learning is independent of direct sensory contact with another human being, cannot be denied. Even where there is acceptance of the need for human beings as teachers of children, there are also managerialist and technicist views representing a philosophical position that tends to see teachers as functionaries. A recent indication of how prevalent this view has become is the proliferation of statements of professional standards and formal induction schemes for new teachers (Howe 2006). As we have argued elsewhere (Author1 et al, 2008), it is not the statements in themselves that are the primary focus of concern - one can understand the need for statements on professional competence in the name of public accountability - but their implicit and concomitant presumptions about the nature of teaching and, more specifically, learning to teach.

Consider, for example, the Standard for Full Registration (SFR), with its associated Induction Scheme, for new teachers in Scotland (GTCS 2001, 2006). This is regarded by many countries, along with its associated Induction Scheme, as a model worth emulating, though it is not included in the review by Howe (2006). We choose it, therefore, not to single it out for criticism but because that is our working context and also because it has international recognition. This standard (the SFR) was formulated by a group that represented the full range of 'stakeholders' in teacher education and admirably includes values and recognises personal commitment as a teacher. The SFR gives a brief acknowledgement of the notion of 'holistic' competence but this tends to be overlooked beside the main list of specific competence statements. One is not inclined to argue against any particular one of these statements on an individual basis. We might all agree that 'registered teachers have detailed knowledge and understanding (of the curriculum)' and 'communicate the purpose of lessons and activities ... in a stimulating manner' (GTCS website), for example. The problem lies in their collective array as an imposed guide or prescription for the new teacher in school. To put it another way: if it takes ten commandments to start a religion, how many competences does it take to become a teacher (Stronach, in Author1 et al 2007).

It is argued that the rhetoric and formulation of standards is not about standards of practice but about standardisation, an adherence to a 'technical/managerial precept that one size fits all in successful teaching' (Ozga 2000: 227). The policy community have tended to project formal standards and support schemes as the route to quality, even as the intended means of directing the learning experiences of neophytes across diverse working contexts. Yet these standards as officialised entities have little if any foundation in empirical evidence and tend to adopt an ideological stance on how things ought to be. Whatever theoretical framework may underpin the various 
statements is rarely made clear; at worst, they are atheoretical in conception and imply a philosophy based on a managerialist need to control and standardise, an agenda which denies complexity and is delivered instead 'through target setting, monitoring and disciplining of the teaching profession' (Shain and Ozga 2001: 117).

Our research on new teachers was aimed at developing a grounded theory (Glaser and Strauss 1968) of early professional learning (see the Early Professional Learning Project website) and was conducted within a naturalistic paradigm (Lincoln and Guba 1985). Findings revealed a striking contrast between the experiences of new teachers in schools and their development through use of professional standards. In some 370 open and semi-structured interviews with 133 new teachers in their first year of teaching, across 34 Primary and Secondary schools, there was but one favourable mention of the standard (SFR) as an aid to development. The other few mentions it did receive were about its intrusion as a bureaucratic requirement for completion of an official but impersonal interim report, half way through the year:

It just must be so bland having to read a list of dates and it doesn't actually give anything of me you know 'Rachael the teacher'. It's just like a ticky box style of a form and in some cases I did put in a lot of work and to an extent I would have liked to have blown my own horn about it, saying I put in all this work and look what I have achieved, whereas no I just put in fourteen- eleveno-four $(14 / 11 / 04)$

I would be reading and half way through I would just give up in disgust.

I found it really dry... it wasn't seeking to find anything about me personally as a teacher.

Our analysis of the extensive narrative data base of the EPL Project led to seven dimensions of new teacher development: cognitive, emotional etc. .... . Although we recognise that this categorisation merits further discussion on its terminological precision (for another paper) - we actually describe the dimensions in terms of conceptual clusters or domains such as emotional/affective/feeling - it is nevertheless evident from our data that the emotional and relational are far more prominent in accounts of experience than the cognitive, as in codified knowledge of curriculum, classroom skills and standards, for example. Learning to teach appears to be experienced as the process of becoming a teacher, an affective transition principally dependent on relationships with colleagues and children taught (Author1 et al 1994; 1997).

Of course this phenomenon of 'learning as becoming' is not entirely new. The literature on the question of what it means to learn to teach, or to become a teacher, suggests that this inchoate query is perhaps more poignant than it appears. The theoretical schism tends to be between those who presume that you can learn, or be taught, to teach from some limited epistemological base and those, fewer perhaps but part of a long tradition, who see entry into teaching as an initiation, a rite of passage (e.g. Eddy 1969). Having addressed elsewhere the relational dimension of early professional learning in terms of new teachers' relationships with colleagues (Author1 2009), attention in this paper is given to the nature of the embryonic relationships between new teachers and the children they teach, the other crucial aspect of the 
relational dimension that is arguably a defining distinction of the work that teachers do.

\section{The views of children}

Our narrative data base consists of interviews with new teachers and so is limited to their perspective. We are aware, however, of the growing importance of the child's perspective. As far back as 1984, Hargreaves found that 'even the experience of being consulted for the purposes of the survey had improved pupils' attitudes and concluded that a shift was urgently needed in the way that pupils are treated in the wider aspects of school life'. More recently, Rudduck (1999) has proposed that we should see pupils as expert witnesses in the important task of school improvement, and Heron et al (2005) argue that pupils have become more sophisticated as consumers of education, able to formulate constructive comments on teaching, classroom activity and school life in general - not surprising perhaps as they simply spend much more time observing teachers in action than colleagues or researchers. We sought to explore this perspective separately. Given the concerns voiced in the last decade or so over the soft story-based evidence of much educational research (e.g. Tooley and Darby 1998), we decided that it was worth exploring how we might devise a quantitative indicator of children's views of their new teachers. The development of this indicator was led by one of the research team and became known as cepsati (classroom environment and pupil satisfaction indicator). A full account of its development is given in Gray et al (2006) but here we limit ourselves to what is relevant for this paper.

Cepsati was designed to be a formal but relatively simple survey instrument, nonthreatening to either new teachers or their pupils. It included teaching and learning activity in the classroom as well as teacher characteristics and so overlapped classroom environment research (Gray et al. 2006: 2; 3). Permission was obtained to adapt WIHIC (What Is Happening In this Classroom?), an instrument developed in Australia by Fraser (1998). Our EPL iteration drew on the expertise of six teachers seconded part-time from schools to join the project research team. They tested the indicator with some 200 pupils in their own schools by eliciting descriptions from pupils about their (new) teachers, what they did to help them to learn, or what they did that inhibited learning. With the teacher-researchers, we identified 47 separate statements from children.

Cepsati was administered on three occasions, more or less equally spaced, throughout the school year, with the new teachers being asked to choose two of their classes to participate. Questionnaires were returned by 53 (65\%) of the 82 participating new teachers in 14 schools, yielding 1148 responses in round 1, 1498 in round 2, and 605 in round 3. By submitting responses (n1089) from round one to principal component analysis (using SPSS version 12.0), we were able to identify those items or variables of the original 47 that fell most clearly into suggested dimensions of classroom experience and thus create a shorter, 14-item 'super'-cepsati (some unnecessary parts eliminated ruthlessly!). For the later primary school phase of the project, this was further refined into a 12-item instrument with simpler language for younger pupils. 
For the purpose of developing super-cepsati, "the teacher knows the class well" was preferred to "the teacher knows my name", given the former's higher loading within component one, as well as on the evidence of individual pupil comments, which tended to indicate a broader whole class perspective (and knowing class names overall?). For the later primary stage, after discussion with teacher-researchers and the primary teachers themselves, the item was further simplified to 'the teacher remembers my name', thus effectively recovering one of the original 47 items that was too statistically similar. Indeed, 'the teacher knows my name' went from a low loading (.397) item in component 1 to the second highest loading (.641), and therefore a defining item, of component 5 (the three highest loading items in each component offer the best clue as to what the component represents). Our interpretation of this is that new teachers were using their knowledge of pupils' names and the class in round 1 to establish relationships, but by the time of round 2 they were able to operationalise their knowledge of pupils' names and the class in the service of teaching and learning.

\section{What's in a name?}

Statistically speaking then, knowing the names of the individuals in the class, and more generally knowing the class, is identified as an important variable. This was highlighted in one interview, Valerie at Denniston High School, as a moment of panic during the class completion of cepsati when a girl in her class (Lisa) asked if she knew her name:

Well one of my first years said 'Miss, what's my name?' and I thought 'Oh my God what is her name?', and I said to her a couple of seconds later 'Lisa', and she said 'that's fine Miss'. She was questioning does she know my name.

This was some five months into the first year of teaching and by that time we might agree that knowing each name is a reasonable expectation of the new teacher, in contrast to the first month or so. Knowing individual names may be interpreted as an early step in building relationships, but only as part of that rather complex and fraught process.

The narrative data from the EPL study in general reveals how new teachers think about children over the first few months of teaching. There is little mention of achievement or performance in tests - perhaps it is too early for that - but more about getting to know them in a fairly fundamental way. This is much more than friendly conversation, which they tend to be wary of, but about getting to know the world of the school, and the children who inhabit it. Understanding them as individuals and relating to them accordingly is much more than a mere task of administering levels of supposedly differentiated materials. Teachers need to 'know' the individual children they teach as different individuals in order to be fully accepted and this needs to be somehow conveyed to, or understood by, the children themselves. Of course, pupils are getting to know 'their' teacher as well and, as a number of studies have shown (e.g. Hay McBer 2000, Brown and McIntyre 1993), pupils see their teachers as human beings and can identify human traits, qualities or characteristics that they have.

Lisa wanted to check that the teacher did indeed know her name and, at one level, she is carrying out a basic factual check (in order to answer the cepsati question). 
However, the statistical analysis shows that remembering an individual pupil's name correlates highly with knowing the class. At a deeper level, the logic is perhaps that if you know my name then you probably know other names too and therefore 'know' the class. And could we further infer that if the teacher knows the class, then she cares about the class? If we accept the validity to the statistical correlations, then it would appear that remembering names and knowing the class are part of pupils' perception of the new teacher as someone who is 'helpful when I am struggling with work' or who 'keeps the class under control', or who 'treats me with respect', or who 'makes lessons fun' or who 'takes time to explain things when we don't understand them' - and who is thus accepted collectively by the pupils in the class as a good teacher, as their teacher.

It is of course a customary expectation to know the names of people with whom you would claim to have some kind of relationship. Some of us are better than others in this respect and some indeed make a point of remembering the names of people they meet infrequently. In some cases, this may be a superficial display of care but on the whole it is probably an admirable ability if accompanied by sincere interest. For the new teacher, it seems to be of unarguable importance, the only question being the number of weeks it reasonably takes to get to know the names of pupils or to commit them to memory; a common advocacy is to write names on a class seating plan. Valerie's panic is that she will lose face professionally through the public fact of not knowing or forgetting the specific pupil's name.

Perhaps the greatest part of name knowing is in what it reveals to others about your interest in them as individuals. For Valerie, this is about whether she herself is seen by them as seeing them as 'her' class. She has a need to be seen by them as interested in them, enough at least to know their names by this stage (some five months into her first year), on the way to knowing them more fully in a relationship that still has to (and that must) develop further if she is to be accepted as 'their' teacher. The pupils need to gain a secure sense of being known but, in the process of this happening, the new teacher also needs to become secure in her sense of acceptance as a teacher, as 'their' teacher.

This sense of acceptance involves what is commonly referred to as 'discipline' or 'control', basically good order and behaviour in the classroom. The fraught experience of new teachers in striving to achieve good order are apparent in the several dimensions of becoming a teacher but the most emotionally charged tends to be the relational dimension. This can be manifested in interactions with colleagues, but the tears of failure do tend to be shed most painfully when you lose the classroom. Valerie does not appear to have suffered quite so severely but still she recognises the risk of 'fun' lessons tipping into 'chaos' as she strives to achieve the elusive classroom equilibrium between establishing relationships and having control.

And quite a lot of them wrote, she doesn't make her lessons interesting, they are boring, which is quite bad because you think that you are just being new and you have fairly new ideas.

(Interviewer - So did that make you think a wee bit more about things?) 
It did yes, but I never did anything. I know it is terrible, I tried to start with. I tried so much to make my lessons like that but then I was just like my God my classes were just chaos. I just need to just get on top of my classes first before I try and do anything fun, because first and second years you give them something fun and they just go... and you have not got a relationship where they know they can't do certain things, it just gets out of hand, so I did to start with but then I just stopped...

This striving for equilibrium is illustrated through the use of a name by another new teacher. A few months into teaching, Kerry knows the names of her class but at the level of knowing the individuals who have those names. She is accepted as their teacher but feels a need to reciprocate further in one relationship through personalising her naming of the individual:

Instead of standing there, well talking the way that I probably should as a teacher. I will be more slangy with them because that is what they understand and I will be, not their friend, but I will be more friendly with them than what I probably should be. I call one of the boys, I say, "Come on Shauny Shaun," and it is like, nobody calls me that, just you. You know, he appreciates that, but I would never do that with any other class but that is what they need. .... I started thinking ... I need to respond to you the way that you need me to.... and that has worked (Kerry)

\section{Ontological security}

The process of becoming a teacher is essentially defined by this evolving relationship between the class and the new teacher. In developing his concept of the 'pure relationship', Giddens (1991) argues that children gain ontological security from their teachers / in the classroom. The evidence from our transcribed interviews and the statistical correlates of knowing names and classes indicates that new teachers also gain ontological security from their pupils, a felt sense of confidence that they are becoming seen and known as teachers. Although the transcripts reveal little insight into the epistemological or pedagogical basis of how new teachers develop, cepsati does contains items related to pedagogy that indicate pupils are being taught: 'the teacher takes time to explain things when we don't understand them' or 'I experience different activities during the lesson', for example.

New teachers' sense of themselves, however, is portrayed through the narrative data in terms of changes in, or observations they make about, themselves that are taking place in order to become teachers. The transition is thus experienced as ontological rather than epistemological. It is not about naïve notions of applying knowledge or about learning techniques or skills. We thus conclude that the early professional learning experience can be evidentially construed in terms of the attaining of reciprocal ontological security: the establishment of a relationship in which pupils in a class need from their teacher a secure sense that they are known and that they matter, but also in which new teachers depend on their pupils for secure knowledge that they are accepted and identified as their teacher. Reciprocal ontological security (ROS) can define becoming and being a teacher. Once ROS is established you have a teacher identity. It is pupils, individually and collectively as a class, who confer that status. The gift of teacherhood is awarded by pupils - and only they can give it - in 
exchanges like that between Kerry and Shauny Shaun when she senses that he appreciates the appellation evoked by her awareness of the 'need to respond to you (Shaun) the way that you need me to': the use of a pet name to signify reciprocation in a developing relationship.

Colleagues may make and offer their judgements on competence but they too ultimately have to base that view on the response of the children taught by the teacher, their progress and behaviour and ultimately whether there is a sense of pupil satisfaction and acceptance. Could you reasonably judge a new teacher to be competent while simultaneously noting that her pupils do not see her as good enough? The official standard is too general and remote from actual experience to be useful in describing or assessing this critical transition. Is it surprising that it receives little mention and is seen as largely irrelevant?

The personal stories that comprise the narrative data convey a clear sense of a changing self. 'You have to give of yourself but not be yourself', in the words of one beginner, typify a kind of struggle with the self, a self that is transforming into a teacher. The ontological essence of this transition is an emerging self-as-teacher identity, to adapt Giddens' (1991) notion of self-identity. Hoveid and Hoveid (2004) also invoke the Norwegian philosopher Schibbye's (2002) notion of the 'relational self' to convey a notion of agency in a self that is nevertheless intrinsically dependent on pupils (and significant others) for its emergence and expression. We thus broadly equate the idea of reciprocal ontological security in this specific context (the new teacher in school) with the emergence of a new identity, that of teacher. Of course, neither identity nor ROS is explicitly referred to in the data. New teachers are patently not saying in interviews that they are seeking ontological security or that they are aware of their evolving identity - we would be suspicious if they were - but it is strongly implicit. One beginner, for example, recognises the emergence of 'humanity' and 'humility' within herself - not qualities specified, or perhaps specifiable, in the standard - as she comes to terms with the realities of life experienced by some children in her class. Another becomes aware of her 'teacher mode' with children carrying over into her everyday behaviour:

Personally I find it difficult to get out of teacher mode. I've gone home and I've got into trouble from my mum because I used the tone and words I would use to pupils like 'stop speaking to me like that' and she just looked at me and said 'you're not a teacher now you know', and I said 'what?' because I didn't realise I was doing it, and my boyfriend's always on at me, saying stop treating me like one of your pupils ... That's one thing I'm definitely struggling with, speaking to people out of the classroom like pupils!

We accept that identity, in a general sense, is multi-faceted and changing over time; it is something we constantly renegotiate during the course of our lives (Wenger1998), and with respect moreover to 'multiple convergent and divergent trajectories' (ibid.: 154). Our grounded theory is that, for the beginner in teaching, the trajectory of identity formation can be better appreciated as a multi-dimensional experience, moving in one main direction, namely establishment as a teacher, the essence of which lies in mutual knowledge and confidence in the classroom - a reciprocal ontological security. It is a journey that lasts anything from several weeks to several 
months, perhaps a year or more for a few. For a very few, the journey does not reach its intended destination.

We are thus guided by our grounded theorisation to a particular notion of identity and away from glib assertions based on misappropriated sociology. A new teacher may very well be white or black, rich or poor, a member of a church or golf club, but a sociological concept of identity that is dependent on social classes and groupings such as these (refs), adds little to, and potentially detracts, and distracts us, from the particular phenomenon of becoming a teacher. Such group belongings may well be part of their identity as a complete social being but, at that stage in one's life, typically the first few months in teaching, a new self as a teacher has to emerge - or be invented, as Stronach (2010) puts it. If successful, then this of course means being accepted into a new grouping (of schools and teachers). We might speculate that once that membership is established, it then becomes one other face of a new multiple sociological type of identity and invoke Deleuze and Guattari's prescription for the rhizomatic imagination, which, 'rather than analysing the world into discrete components, reducing their manyness to the One identity, and ordering them by rank ... synthesizes a multiplicity of elements without effacing their heterogeneity or hindering their potential for future rearranging (to the contrary)' (Massumi 1988: xiii).

\section{Further connections}

Our identification of the emotional and relational as important dimensions of (new) teachers' lives finds support in the work of Hargreaves $(1998,27)$, who sees the emotions of teaching as 'not just a sentimental adornment ... (but) ... fundamental in and of themselves' and also Eraut (2004), who argues that the emotional dimension of professional work is much more significant than normally recognised. Notwithstanding this corroboration in the same field, our use of grounded theory avoids the conscious premature use of any particular lens through which to view the phenomenon under study. We aspire to resist the premature imposition of a favoured theory or philosopher.

As our data analysis develops, however, we inevitably begin to make connections from our own reading, ongoing literature searches and reviews and of course discussions with colleagues. In a preliminary exploration of beginners' learning (Author 1 et al $1994 ; 1997)$, we found general acknowledgement that learning to teach was emotionally demanding and threatening to self-esteem but that understanding the process led us to consider the importance of friendship in education. White (1990), for example, invokes Aristotle and Bacon in arguing that friendship allows us to marshal our thinking and that more intimate acquaintance means that advice tends to be given in one's interest. Ultimately this contributes to greater job satisfaction of individuals and the working environment of the organization. More recently, we have found that our notion of relationality is consonant with the view that the quality of work done in organisations depends on the ethical nexus in the workplace (Hinchcliffe 2004).

In this vein, we have found Giddens (1991) to be helpful in making sense of our findings. His argument for the recovery of the self in sociological writing on identity finds support in the case of people becoming teachers; equally so with Schibbye's 'relational self' in evoking the ontological reciprocity that characterises the new teacher's journey. A further philosophical warrant for our emergent theory of identity 
as ROS and the place of self comes from Bahktin's view (in Holquist 1990)that the self should not be studied as an abstract entity and that it only makes sense through particularity and situatedness. It is when people talk about their actual experiences in particular situations - in this case, individual narratives about becoming a teacher in a school - that there is a clear and undeniable sense of something happening to them as individuals. The use of self here is decidedly not as some abstract or imposed notion but in recognition of individually felt series of sensations, affective rather than consciously reflected on. Yet it was through serendipitous parallel reading that the writing closest to our sense of a self in new teacher development was found. In a poem written during MacCaig's early metaphysical bent, we find the cogent expression of a truth in a simple stanza:

Self under self, a pile of selves I stand

Threaded in time and with metaphysic hand

Lift the farm like a lid and see

Farm within farm, and in the centre, me

(from 'Summer Farm' by Norman MacCaig)

\section{Learning and standards}

It is important to recall that our initial research interest was in learning, the learning of new teachers specifically, and that we were directed by the data to see the process of learning as more of an experience of becoming. That we found little evidence of specific learning of a more cognitive kind, such as developing competence in classroom management, curriculum or subject knowledge, teaching techniques or methods, may be of some concern to the makers and followers of policy. This may be contrary to their expectations. We are open, however, to the possibility that our findings may be methodologically influenced. A different method that sought to elicit specifically what competences or professional craft knowledge new teachers actually acquire, using a more focussed and tightly structured approach might well generate additional insights into the learning experience. The empirical evidence that little explicit cognitive development is taking place is not advanced as a dogmatic assertion. Our hunch is that what they bring from their ITE courses and biographies is temporarily put aside, submerged or unseen in a more complex and transformative experiential whole. They know enough to get by while they are caught up in finding their new selves in a new world, that of a teacher in a school.

Nevertheless, the empirical conceptualisation that we have developed reflects a wider theorisation of learning. Bosma and Kunnen (2001, p.xiii) for example, argue that learning is an inherently emotional process embedded within a relational context and that this is associated with the development of self and identity. Illeris $(2002,229)$ finds that very special and demanding situations, often with a crisis-like character (apparent in our narrative data but also through common anecdote) can lead to deep and comprehensive transformative learning processes that include simultaneous change in all the three learning dimensions (cognitive, social, affective) and have to do with the very identity of the learner. Such general descriptions accommodate and are supported by our grounded data and interpretation, strengthening the case for seeing beginning teaching as a deep process of personal change in which there is an emergence of a teacher identity. 
So what of the competence-based occupational standard (the SFR)? Other than occasional brief mention of the bureaucratic requirement to complete the interim report based on the standard, there is no explicit link. We see it as a kind of dictionary or reference book containing elements of a language but not a language itself. It is a set of contextualising professional statements but not itself the text of that professional development, which is written in the experience of each individual and represented imperfectly in each narrative simulacrum of the experience. Such 'natural quantum rhythms of life' as Rodriguez (2002: 6) argues 'undermine any stability and consistency that ... language strives to foster'. Whatever may be uncovered about a stricter dimension of cognitive development, our evidence opposes any assumption or imposition of a neat learning model of the ubiquitous 'knowledge - skills - values' framework of standards. It refutes linearity of learning to the extent that it is not just loss or absence but 'repression of pluri-dimensional thought ... that begins to sterilize the technical and science economy that it has long favoured' (Derrida 1991: 50).

The standard may indeed be a reference book for a life in teaching, understandable at deepening levels with experience and reflection. The policy mistake is to see it as more than a public statement to which teachers are accountable, to think that it actually guides or governs practice. In the interests of constructive engagement, we have suggested (Author 1 et al 2008) that the standard might be broadened to encompass other dimensions of development / learning (holism in Scotland), that it might take account of experience or be developed by teachers themselves, as done in Holland (Storey 2006), and indeed that there is a possible connection between the discourses in the concept of handling difference in teaching.

\section{Concluding discussion}

What then does our account contain that is theoretical and philosophical in relation to teacher education? Firstly, we developed a grounded theorisation from a narrative data base of interviews to give a broad based understanding as a foundation for further focussing. We recognise the limitations of grounded theory, as adumbrated, for example, by Thomas and James (2006) but have nonetheless found it particularly useful in affirming the essence of early professional learning as a phenomenon and in identifying questions worth pursuing, sometimes by quantitative means. The theory generated also takes account of practice; indeed it is rooted in practice. Rather like Stokes (2007), we think that applying theory to practice can all too often fail to recognise the complexity of a situation and so stay remote from the actual context of that practice. Thus we build our theory from the ground and, in so doing, attach much importance to the empirical data, both qualitative and quantitative, that we collect and analyse. To that extent, we are therefore respecting a more scientific, evidencebased paradigm.

Once a concept (reciprocal ontological security, in this case) begins to emerge and crystallise, we then seek to see it in relation to extant conceptualisations within the literature. This search tends to take us into other disciplines such as philosophy or sociology. Our aim is to find the extent to which our emergent themes can be illuminated and possibly articulated through other discourses. In this way we begin to have some confidence in particular theories or philosophical positions that accommodate or help support and express the phenomenon under investigation. Thus we would attach relevance to arguments and theorisations by Giddens, Illeris, Bakhtin, 
Deleuze and others referred to earlier. Interestingly, in our preliminary explorations of learning in other professions, as part of our wider reading, we were struck by the premise of Benner and Wrubel's work $(1989$, p20) that theory derived from practice

... is based on the Heideggerian view that practical engaged activity is more basic than, and is prior to, reflective thinking. The practical world is more complicated and dynamic than can be captured by any formal theory.

Their starting point of practice before theory is much more explicit than our own initial inclination. It was only as the evidence unfolded and yielded new understandings that we became aware of our implicit closeness to a Heideggerian phenomenology. Our empirical work on new teachers that revealed the importance of the relational and ontological over the language of standards echoes statements such as:

the ontological question takes precedence over the epistemological one ... the question of being is prior to the question of knowing ... the answer to the question of knowing arises out of the answer to the question of being (Benner and Wrudel p.41).

human capacities are best described in terms of possibilities and skilled practice, and not just in terms of how well the person measures up to predetermined, context-free criteria of performance (p399)

we require a language and science that captures the nature and intent of these practices as they are carried out in real contexts and real relationships (p403).

Like Benner and Wrubel (1989), we ourselves are not philosophers, but we find that, used selectively against a base of grounded theory, we need to draw on philosophy to help express and conceptualise phenomena - and further legitimise our interpretation of these same phenomena.

The need for such excursion is also driven by the relative absence in teacher education research of a credible theoretical reference framework for understanding early professional learning and development. Too much of the literature accepts policy rhetoric as a given wisdom. Educational research has been criticised for its lack of rigour and much of the literature has been seen as too remote, unconnected and even unrepresentative of the real world of schools (we recall a meeting in the late 1990s in which a teacher said she would scream if one more academic used the phrase 'reflective practitioner'). Recent academic preoccupation with postmodern thinking is interesting enough for those of us privileged to engage with such thinking in our working lives, but it tends not to be received so enthusiastically by beginners in teaching - or their educators - who have pressing challenges of a more existential kind. The recent article by Clarke (2009), for example, drawing on Foucault and Deleuze, does at least recognise teacher identity as an ethical self-formation but that position can be strengthened to the point where it can be claimed as a theoretical concept, grounded in empirical work and developed, as we have attempted to do in this paper. To the extent that our work is located within social science, then it lies with Flyvbjerg's (2001) argument that practice needs to come before discourse and that, if 
it is to be more than a sterile academic activity, research needs to acknowledge practical wisdom.

The opportunities afforded to research on teacher education, therefore, through national initiatives such as the UK Economic and Social Science Research Council's substantially funded Teaching and Learning Research Programme cannot be overlooked. The associated growth in other sites of activity across many countries signifies a huge global enterprise of teaching and teacher education, that is not just about practice by teachers and teacher educators in their institutions on one hand and research conducted separately in academe - by sociologists, psychologists and philosophers - on the other, but about serious research attention by teachers and teacher educators as researchers too. The importance of seeing practice as problematic and researchable by practitioners is paralleled in other professional areas, as exemplified by Stokes (2007) in illustrating in depth the ethical complexity of questions facing nurse educators in making decisions about beginners in nursing.

Credit has to be given to the work of Eraut and Hargreaves in the same broad field of professional learning and development. Their recognition of emotionality and relationality as undervalued dimensions of learning has been an important step forward, as has the work of Day (e.g. Day, Kington, and Gu 2005), in providing quantitative evidence of the centrality of teacher identity in teacher effectiveness. Such empirically derived findings have given corroboration of our conceptual array informality, becoming, the emotional, the relational and the ontological - and the theoretical substance of our argument. It appears that we have become - and have had to become - eclectic in argument, blending the hunches of the experienced practitioner within different discourses, drawing on a range of theoretical and philosophical perspectives, rather than prematurely impose any single view, though we now have grounds for suggesting that certain theorists and philosophers in this paper offer ideas that are worthwhile and relevant for initial philosophical inquiry in teacher education. To engage in any meaningful way with theory and philosophy in teacher education, it seems to us that it could scarcely be otherwise.

\section{References}

Benner P. and Wrubel J. (1989) The Primacy of Caring: Stress and Coping in Health and Illness Addison-Wesley Publishing Company California Bosma, H.A., and E.S. Kunnen. 2001. Identity and emotion. Cambridge: Cambridge University Press.

Brown, S. and McIntyre, D. (1993) Making sense of teaching Bucks, OUP

Clarke M. (2009) The Ethico-politics of Teacher Identity Educational Philosophy and Theory 41, 2, $185-200$

Day, Kington, and Gu (2005)The role of identity in variations in teachers' work, lives and effectiveness. Paper presented at the ESRC Seminar Series, in Nottingham.

Derrida, J. (1991) 'Of Grammatology' in P. Kamuf (Ed) A Derrida Reader: Between the Blinds, New York: Columbia University Press.

Early Professional Learning Project (http://www.strath.ac.uk/curricularstudies/eplproject/ (accessed 9 July 2009)

Eddy, E.M. (1969). Becoming a teacher. New York: Columbia University/Teachers College Press. Eraut M. 2004. Informal learning in the workplace. Studies in Continuing Education 26, no. 2: 247-73. 
Fraser, B. (1998) Classroom Environment Instruments: Development, Validity and Applications LearningEnvironmentsResearch,1/1,1998, Taylor Peter C, Fraser Barry J \& Fisher Darrell L (1997) “Monitoring Constructivist Classroom Learning Environments" International Journal of EducationalResearch27,4,293-302

Flyvbjerg, B. (2001) Making Social Science Matter (Cambridge: Cambridge University Press) Glaser B. \& Strauss A. (1968) The discovery of grounded theory: strategies for qualitative research (London, Weidenfeld \& Nicolson).

Giddens 1991Giddens, A. 1991. Modernity and self-identity. Cambridge: Polity Press.

Gray, P., Author2, A. and Author1, J., with David Dodds, Lesley Easton, Colin Smith, Phil Swierczek and Lesley Walker (2006) 'She is the best teacher in the world': surveying pupil opinion in Scottish secondary schools Paper presented at BERA 2006, Warwick

GTCS. 2001. The standard for full registration appendix 1. Edinburgh: GTCS.

GTCS 2006. http://www.gtcs.org.uk/web/site/Probation/StandardFullReg (accessed August 2, 2006).

Hargreaves, A. 1998. The emotional politics of teacher development. Keynote address to AERA, San Diego, CA.

Hay McBer Report (2000) A Model of Teacher Effectiveness

www.dfee.gov.uk/teachingreforms/mcber

Hinchliffe G. (2004) Work and Human Flourishing Educational Philosophy and Theory 36, 5, 535-547

Holquist, M. 1990. Dialogism: Bakhtin and his world. New York: Routledge.

Hoveid, H., and M. Hoveid. 2004. A teacher's personal language: Ways of constructing inclusion

and diversity in teaching. Paper presented at the annual European Conference on Educational

Research, 22-25 September, in Crete.

Howe E.R. (2006) Exemplary Teacher Induction: An international review Educational Philosophy

and Theory, Vol. 38, No. 3, 287-297

Illeris, K. 2002. The three dimensions of learning. Leicester: Niace Publications/Roskilde

University Press.

Lincoln, Y.S. and Guba, E.G. (1985) Naturalistic Inquiry California, Sage Publications

MacCaig N. (1990) 'Summer Farm', in Collected Poems (Chatto \& Windus, London)

Massumi, B. (1988) 'Translator's Foreword' in G. Deleuze \& F. Guattari, A Thousand Plateaus:

Capitalism and Schizophrenia London: The Athlone Press.

Author1 (2010) Who can you count on? The relational dimension of new teacher learning In

Author1 and Author2 (2010) Improving Learning in a professional Context London Routlege

Author1 J., Author2 A., Corbin B. and Gray P. (2008) Finding an identity and meeting a

standard: connecting the conflicting in teacher induction Journal of Education Policy Vol. 23, No. 3, May 2008, 287-298

Author1,J., Boreham N., Corbin B. and Stronach I. (2007 Perspectives on Early Professional Learning Keynote session at the annual conference of the International Society for Teacher Education, Stirling University, June 2007

Author1, J., Cope, P., Inglis, W. \& Stronach, I. (1997) The Student Teacher in School: Conditions for Development Teaching and Teacher Education 13, 5, 485-498

Author1, J., Cope P., Inglis W. and Stronach I. (1994) Current Realities in the Student Teaching Experience, Teaching and Teacher Education 10(2), 219-230.

Ozga, J. (2000) Education : New Labour, New Teachers, in J. Clarke, S. Gewirtz \& E.

McLaughlin (eds) New Managerialism, New Welfare? London: Sage

Rodriguez, A. (2002) 'Redefining our Understanding of Narrative', The Qualitative Report, http: //www.nova.edu/ssss/QR/QR7-1/rodriguez.html, (accessed 4 December 2004).

Rudduck 1999

Schibbye Schibbye, A. L. L. (2002) En Dialektisk Relasjonsforståelse i Psykoterapi med Individ, Par og Familie (A Dialectical Understanding of Relationships in Therapy with Individuals,

Couples and Families), Oslo: Universitetsforlaget.

Shain, F., and J. Ozga. 2001. Identity crisis? Problems and issues in the sociology of education.

British Journal of Sociology of Education 22, no. 1: 109-20.

Stokes G. (2007) Different Voices in Nurse Education Educational Philosophy and Theory, Vol. 39, No. 5, 494-505 
Storey, A. 2006. The search for teacher standards: A nationwide experiment in the Netherlands. Journal of

Education Policy 21, no. 2: 215-34.

Stronach I. (2010) The invention of teachers: how beginning teachers learn In Author1 and Author2 (2010) Improving Learning in a professional Context London Routlege

Thomas, G. \& James, D. (2006) Reinventing grounded theory: some questions about theory, ground and discovery, British Educational Research Journal, 32(6), 767 - 795

Tooley, J. and Darby, D. (1998) Educational Research: a critique (London: HMSO)

Wenger, E. (1998) Communities of Practice: Learning, Meaning, and Identity, Cambridge:

Cambridge University Press.

White, P. (1990) Friendship and Education, Journal of Philosophy of Education 24, 1, 81-91 